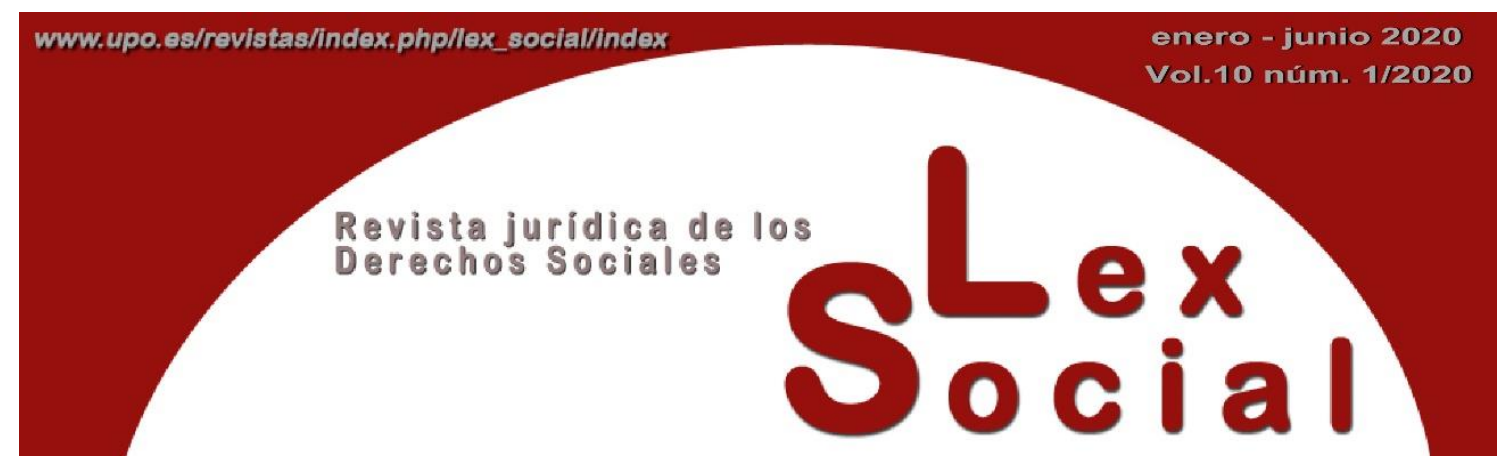

\title{
LAS DEFENSORÍAS DEL PUEBLO Y LA IMPLEMENTACIÓN DE LOS DERECHOS SOCIALES: DÉFICITS Y RETOS DE UN ENFOQUE INTEGRAL DEL DERECHO
}

\section{OMBUDSMAN INSTITUTIONS AND THE IMPLEMENTATION OF SOCIAL RIGHTS: DEFICITS AND CHALLENGES OF AN INTEGRAL APPROACH TO LAW}

CARMEN SALCEDO BELTRÁN

Profesora Titular Derecho del Trabajo y Seguridad Social Universidad de Valencia ${ }^{1}$

Artículo recibido el 26 de octubre de 2019

Artículo aceptado el 10 de noviembre de 2019

\section{RESUMEN}

Entre las funciones a realizar por los defensores del pueblo se encuentra la implementación de todos los derechos humanos, entre los que se incluyen los derechos sociales. En coherencia con ese cometido, existe un tratado internacional, la Carta Social Europea, complementada con la significativa jurisprudencia emitida por el Comité Europeo de Derechos Sociales, que debería ser el vector de cualquier actuación que efectúe en torno a ellos. El presente estudio, en primer lugar, demuestra esa afirmación a través de dos derechos reconocidos expresamente, de carácter transversal, el derecho a la protección contra la pobreza y la exclusión

\footnotetext{
${ }^{1}$ El presente estudio forma parte de las actividades grupo de investigación internacional "Derechos Humanos y Carta Social Europea" de la Universitat de València (GIUV2013-148). ORCID: https://orcid.org/0000-0002-6529-2396. ResearcherID: Z-5983-2019.

Principales abreviaturas utilizadas: art. (artículo), CE (Constitución Española), CEDS (Comité Europeo de Derechos Sociales), CSE (Carta Social Europea, para la versión revisada se utilizará la misma incluyendo en concreto esa referencia).
} 
social y el derecho a la vivienda-. En segundo lugar, pone en evidencia, con ánimo constructivo, su escasa consideración por las instituciones nacionales de derechos humanos, para finalizar, en tercer lugar, proporcionando líneas de actuación con el objetivo de corregir los déficits detectados y fortalecer estos organismos en un período en el que su existencia es cuestionada en determinados niveles.

Palabras clave: defensor del pueblo, pobreza, vivienda, exclusión social, derechos sociales, Carta Social Europea.

\begin{abstract}
Among the functions to be performed by ombudsmen is the implementation of all human rights, including social rights. In coherence with this mission, there is an international treaty, the European Social Charter, complemented by the case law issued by the European Committee of Social Rights, which should be the framework for any action it takes around them. The present study, firstly, proves this assertion through two expressly recognized rights of a transversal nature, the right to protection against poverty and social exclusion and the right to housing. Secondly, it constructively highlights their lack of consideration for national human rights institutions, and concludes, in the third place, by providing lines of action aimed at correcting the deficits detected and strengthening these bodies in a period in which their existence is questioned at certain levels.
\end{abstract}

KEYWORDS: ombudsman, poverty, social exclusion, housing, social rights, European Social Charter.

SUMARIO

I. Consideraciones previas: debates y cuestionamientos sobre las defensorías del pueblo.

II. Las instituciones nacionales de derechos humanos como garantes de todos los compromisos internacionales integrados en el ordenamiento jurídico.

1. La European Network of National Human Rights Institutions (ENNHIR).

2. La CoE-FRA-ENNHRI-Equinet Collaborative Platform on social and economic rights.

III. Los derechos sociales como vectores de la actividad de los ombudsman: la aprehensión de la Constitución Social de Europa y de la jurisprudencia de su órgano de supervisión.

1. El derecho a la protección contra la pobreza y la exclusión social. 
2. El derecho a la vivienda.

IV. La superación de un presente de déficits de conocimiento y aplicación.

$V$. Desafíos y líneas de actuación.

VI. Reflexiones finales.

Bibliografía

\section{Consideraciones previas: debates y cuestionamientos sobre las defensorías del pueblo.}

El inicio del período de crisis ha conllevado que la figura del defensor del pueblo sea objeto de atención en dos sentidos diferentes en nuestro país. Si bien es sobradamente conocido el recurso al mismo frente a vulneraciones de derechos de los ciudadanos, en el año 2013 el Ministerio de Hacienda y Administraciones Públicas, puso en marcha un proyecto para mejorar la eficiencia y eficacia de la actividad pública creando, por Acuerdo del Consejo de Ministros del 26 de octubre de 2012, una Comisión para la Reforma de las Administraciones Públicas (CORA). Su finalidad es fácil deducirla de su título, y así se define en las primeras páginas, en un triple sentido, superar la peor crisis económica en las últimas décadas, corregir los desequilibrios que frenan nuestro crecimiento y crear las bases idóneas sobre las que levantar un nuevo ciclo de prosperidad económica y empleo para los españoles.

Como resultado de los trabajos elaboró un informe ${ }^{2}$ que presentaron la Vicepresidenta y Ministra de la Presidencia y el Ministro de Hacienda y Administraciones Públicas al Consejo de Ministros del 21 de junio de 2013, con más de dos centenares de medidas dirigidas a optimizar y simplificar el funcionamiento de las entidades públicas. Para su ejecución, seguimiento, impulso, coordinación y, en su caso, proponer nuevas medidas se creó por Real Decreto 479/2013, de 21 de junio, la Oficina de la reforma de la Administración (OPERA), con el propósito de velar por su materialización.

Una de ellas ponía la atención en los defensores del pueblo autonómicos, apuntando dudas sobre su operatividad y razón de ser al desarrollar competencias idénticas a las de nivel estatal, con la única diferencia del ámbito geográfico. Concretamente, indicaba que en ese momento existían 11, asociándoles un análisis que mostraba un elevado coste en la tramitación de las quejas y un bajo rendimiento de los recursos humanos si se cotejaban con el nacional (en éste 165 personas tramitan 33.849 quejas frente a los autonómicos en los que 346 personas lo hacen de 38.407).

Previamente algunas regiones los habían ya eliminado. Era el caso de Castilla-La Mancha, por Ley 12/2011, de 3 de noviembre de 2011, Murcia, por Ley 14/2012, de 27

2 https://transparencia.gob.es/transparencia/dam/jcr:b1c69477-9882-41a5-9f6d-5cbb46fa12b4/reformaAAPP.PDF. 
de diciembre, de medidas tributarias, administrativas y de reordenación del sector público regional o Asturias, en virtud de la Ley 2/2013, de 21 de junio, de supresión del Procurador General. Con posterioridad lo hizo La Rioja, con la Ley 9/2013, de 21 de octubre, que suspendía la norma que lo regulaba, la Ley 6/2006, de 2 de mayo, del Defensor del Pueblo.

Todas argumentaron motivos de austeridad del gasto, mayor eficiencia y duplicidad innecesaria de esta institución, al existir la Defensoría estatal que consideraban que hacía la misma labor, no derivándose merma de protección de los derechos de estas regiones, puesto que el nacional permanece ${ }^{3}$. En consecuencia, para alcanzar esos objetivos se propone la asunción plena de las competencias de los órganos autonómicos, resultando un ahorro significativo.

El documento, así como la propuesta aludida, han sido muy debatidos por partidarios y detractores. Los primeros advierten de la existencia de solapamientos, disfuncionales duplicidades y competencias concurrentes ${ }^{4}$, mientras que los segundos denuncian que la reducción del coste no puede ser el único criterio para sostener una decisión política y la discutible premisa de la duplicidad, no existiendo en el caso de dos órganos con funciones similares sino cuando realizan las mismas tareas, es decir, la ineficiencia no deriva de ella sino de la ejecución simultánea de una misma actividad, siendo más recomendable la complementariedad para conseguir una actividad más eficiente de los poderes públicos ${ }^{5}$.

Igualmente, se han pronunciado categóricamente algunas valoraciones doctrinales sobre la utilización interesada de esos argumentos en los medios de comunicación para obtener fácilmente el respaldo de la ciudadanía, y, por derivación, la exhibición de un modelo de operatividad de los órganos centrales. Complementariamente revelan la genuina razón, que no es otra que una nueva configuración político-administrativa que los gobernantes de esa legislatura momento pretendían, prescindiendo de la realización de una «prueba objetiva de utilidad» que superaría la mayoría de los organismos ${ }^{6}$.

\footnotetext{
${ }^{3}$ Similares motivos se han utilizado para la supresión de otros organismos, como, por ejemplo, la del Defensor del Menor de la Comunidad de Madrid, por Ley 3/2012, de 12 de junio.

4 Fernández Rodríguez observa un ámbito competencial común y en los dos sentidos entre la universal del defensor estatal y la del respectivo ombudsperson de una Comunidad Autónoma, referenciando la jurisprudencia constitucional emitida en orden a esclarecer esta cuestión. En "Defensor del Pueblo y defensorías autonómicas: Reflexiones sobre sus relaciones y posición recíproca", Teoría y realidad constitucional, 2010, no 23, http://revistas.uned.es/index.php/TRC/article/view/6922/6620, pp. 263 y 264. 5 Montilla Marcos, J.A., "El Informe CORA", Observatorio de Derecho Público, IDP, 15 junio 2016, http://idpbarcelona.net/el-informe-cora/,p. 1.

${ }^{6}$ Del Rey Ruiz, M. y Martínez Alarcón, M.L., "Vigencia y Necesidad de un Defensor del Pueblo para Castilla-La Mancha", Revista de Estudios Jurídicos, 2013, $\mathrm{n}^{\circ} \quad$ 13, https://revistaselectronicas.ujaen.es/index.php/rej/article/view/1323/1096, pp. 20 у 21, y Calvo Cirujano, F., "La supresión de instituciones en las comunidades autónomas: el ejemplo de Castilla-La Mancha", en AA.VV. (Coord. Pau i Vall, F.), El parlamento y el defensor del pueblo, XXII Jornadas de la Asociación Española de Letrados de Parlamentos, Madrid, 2016, Tecnos, pp. 152 y 153. Subraya éste autor que uno de los aspectos más negativos de ese informe es que obvia el progresivo deterioro de las instituciones constitucionales, añadiendo la falta de previsiones contrastadas y la regulación imprecisa e improvisada.
} 
Junto a esa persecución, que en la actualidad prosigue ${ }^{7}$, convive la otra perspectiva que se corresponde con la defensa de su existencia, la tradicional de defensores de los derechos humanos, al servicio de ciudadanos y supervisor de la actividad de las administraciones públicas, en la que centraré el estudio con la intención de hacer ostensible la necesidad de orientar esa actuación con el Tratado más importante en materia de derechos sociales, la Carta Social Europea. Frente a una realidad en la que se constata, por lo que se refiere al organismo español y autonómicos, una limitada e insuficiente atención, en las siguientes páginas se expondrá la necesidad de corregirla para corresponder real y sólidamente a los requerimientos de la sociedad y al Consejo de Europa en toda su dimensión, que no duda en protegerles y remarcar su rol fundamental como reforzar la democracia y el Estado de derecho.

Así lo ha realizado recientemente la Asamblea Parlamentaria con la adopción el 2 de octubre de 2019 de la Resolución 2301 (2019) sobre la necesidad de un conjunto de normas comunes para las instituciones de mediadores en Europa, que aprueba y respalda los Principios sobre la protección y la promoción de la institución del defensor del pueblo (Principios de Venecia), elaborados por la Comisión Europea para la democracia a través del derecho, en su sesión plenaria de los días 15-16 marzo de 2019 . En ambos se transmite la preocupación por las diferentes formas “(...) de ataques y amenazas, como la coerción física o psicológica, acciones jurídicas que amenazan la inmunidad, la supresión como represalia, los recortes presupuestarios y la limitación de su mandato" o su debilitamiento por los parlamentos retrasando su nombramiento, rechazando los informes anuales o de otro tipo que les presenten, impidiendo el acceso a información o documentación, sometiéndoles a auditorías injustificadas o siendo objeto de ataques verbales por los gobiernos y la clase política, haciendo un llamamiento a observar los 25 principios que lo componen y, con ello, puedan desarrollar su actividad de forma adecuada, sin que se vea afectada su capacidad, independencia e imparcialidad.

\section{Las instituciones nacionales de derechos humanos como garantes de todos los compromisos internacionales integrados en el ordenamiento jurídico.}

Considero fundamental poner de manifiesto desde un principio la significación que tiene la institución de las defensorías del pueblo al servicio de los ciudadanos desde su creación ${ }^{9}$, acentuada aún más en los períodos de crisis que cíclicamente soportan gran

\footnotetext{
7 Véase en este sentido la primera comparecencia del Grupo parlamentario Vox en Andalucía, 28 mayo 2019, solicitando su supresión, http://www.parlamentodeandalucia.es/webdinamica/portal-webparlamento/inicio.do.

8 Se pueden consultar en https://www.venice.coe.int/webforms/documents/?pdf=CDL(2018)025-spa. Véase también con anterioridad, entre otras, la Recommandation du Comité des Ministres aux États membres sur la nécessité de renforcer la protection et la promotion de l'espace dévolu à la société civile en Europe (adoptée par le Comité des Ministres le 28 novembre 2018 lors de la 1330e réunion des Délégués des Ministres), CM/Rec(2018)11.

${ }^{9}$ Sobre el origen de esta institución en Suecia, su imitación por otros países nórdicos y europeos así como su introducción en Iberoamérica véase Álvarez Vélez, en la que se muestran algunas peculiaridades como el caso alemán o el de Reino Unido. En "El Defensor del Pueblo estatal y los defensores autonómicos:
} 
parte de los Estados en la que las restricciones y violaciones de derechos humanos, principalmente de los colectivos más vulnerables, es frecuente.

En la medida en que los principales afectados han sido, y aún continúan, los derechos sociales, la CSE se ha erigido en bastión de su defensa ${ }^{10}$ o elevada al estatus de Constitución Social de Europa en $2014^{11}$. Lamentablemente es muy desconocida por su ubicación secundaria, a la sombra de la otra organización regional, la Unión Europea y también, dentro del Consejo de Europa, del Convenio Europeo de Derechos Humanos. Pertinente es la calificación de $«$ Cenicienta» ${ }^{12}$.

La necesaria implicación de la actividad de las defensorías del pueblo en cuanto a ella es irrefutable, más si se tiene en cuenta que, entre las formas de denominarlos, está también la de «defensores de los derechos humanos»-Commissaire aux drois de l'homme el representante del Consejo de Europa- entre los que se incluyen lógicamente los derechos sociales, con independencia de su ámbito regional, estatal o internacional. Así lo determinaron los Principios de París ${ }^{13}$ al establecer su competencia “(...) en el ámbito de la promoción y protección de los derechos humanos".

A nivel europeo se encuentran evidencias que ponen de manifiesto la orientación en torno a este tratado, directamente con su texto y/o con el Protocolo que prevé un sistema de Reclamaciones Colectivas, de 9 de noviembre de 1995, así como con el Proceso de Turín, ignorado por la mayoría de responsables gubernamentales nacionales, agentes y entidades sociales, frente al difundido Pilar europeo de los derechos sociales. En particular lo haré a través de dos organizaciones que serán analizadas a continuación de forma separada,

instituciones de garantía de los derechos", en AA.VV. (Coord. Álvarez Vélez, M.I. y Vidal Prado, C.), La Constitución Española: 1978-2018, Madrid, 2018, Francis Lefebvre, pp. 269 a 271

${ }^{10}$ Jimena Quesada, L., "El último bastión en defensa de los derechos sociales: La Carta Social Europea". Revista Jurídica Universidad Autónoma de Madrid, 2014, $\mathrm{n}^{\circ} 29$. https://revistas.uam.es/revistajuridica/article/view/5607, pp. 1 a 19.

${ }^{11}$ Puede constatarse en las numerosas menciones del Informe final, entre otras, "Toutes ces initiatives seront menées à bien pour que la Charte sociale puisse, dans l'intérêt de tous, toujours demeurer la Constitution sociale de l'Europe" o "Ce processus serait un pas déterminant pour la relance de la construction européenne car, comme d'aucuns l'ont indiqué de manière emblématique à l'occasion de la Conférence, il est essentiel que l'Europe prenne appui sur les valeurs fondamentales autour desquelles elle a vocation à rassembler les Etats et leurs citoyens - et tout spécialement sur les valeurs de la Charte, cette "Constitution sociale de l'Europe». En Rapport général de la Conférence à haut-niveau sur la Charte sociale européenne, L'Europe repart à Turin, https://rm.coe.int/168048acf9, pp. 43 y 168.

12 Malinowsky, J., "Pour la défense de Cendrillon», en https://70.coe.int/fr/display-story/lasset_publisher/i0obV0uCSWii/content/in-defence-of-cinderella. Véase el análisis completo del autor en AA.VV., (Coord. Huber, D). Artisans de l'europe. 30 témoignages pour 70 ans d'Histoire. 1949-2019, Strasbourg 2019, La Nuée Bleue/Les Editions du Quotidien, pp. 25 a 30.

${ }_{13}$ Principios relativos al estatuto y funcionamiento de las instituciones nacionales de protección y promoción de los derechos humanos, Resolución 48/134.Véase la Resolución aprobada por la Asamblea General el 18 de diciembre de 2014 sobre El papel de los ombudsman, mediadores y demás instituciones nacionales de derechos humanos en la promoción y protección de los derechos humanos, 12 febrero 2015 A/RES/69/168. Sobre ellos y su significación Sánchez Saudinós considera que son una ampliación de mandato nacional. En "Artículo 54", en AA.VV. (Dirs. Pérez Tremps, P. y Sáiz Arnaiz, A.), Comentario a la Constitución Española: 40 aniversario 1978-2018. Libro-homenaje a Luis López Guerra, Tomo I, Valencia, 2018, Tirant lo Blanch, pp. 957 y 958. 
por un lado, la European Network of National Human Rights Institutions (ENNHIR) y, por otro lado, CoE-FRA-ENNHRI-Equinet Collaborative Platform on social and economic rights, no sin antes señalar brevemente las principales notas características del Proceso de Turín mencionado.

Fue lanzado por el Secretario General del Consejo de Europa con ocasión de la Conferencia del alto nivel sobre la Carta Social Europea los días 17 y 18 de octubre de 2014 (conocida como Turín 1), con la finalidad de situar en el primer plano de la escena política la importancia de los derechos sociales acordando que su respeto “(...) es el mejor medio para dirigir a los ciudadanos hacia la participación en los procesos democráticos, de incrementar su confianza en la construcción europea y de combatir el fundamentalismo y la radicalización, estimulando la inclusión y la cohesión social" ${ }^{14}$. Para ello, se llamó la atención de los gobiernos de los Estados miembros del Consejo de Europa y de las autoridades de la UE sobre la importancia de garantizar y de promover los derechos sociales consagrados por los tratados de la CSE en un contexto internacional, en el que la presencia de múltiples problemas relacionados con el ejercicio de esos derechos manifiestan la inexcusable necesidad de adoptar soluciones, en las que sea prioritario reforzar la CSE, en principio, en dos direcciones, dentro del Consejo de Europa y en relación con la legislación de la UE.

En la misma se adoptó un Informe General (Le Rapport Nicoletti) que se erige en su motor al incluir un plan de acción con cinco medidas que, a su vez, se concretan en un conjunto de actuaciones de activación distinguiendo las inmediatas, de las que fijan un medio o largo plazo, en las que se implica a todas las organizaciones europeas, los Estados, las $\mathrm{ONG}^{15}$ y los agentes sociales. Son las siguientes:

$1^{\mathrm{a}}$. Fortalecimiento de la CSE, que se concreta, entre otras, en el impulso de la ratificación de la versión revisada y/o de todos sus preceptos, consolidar su posición y visibilidad, modificar la elección de los miembros del CEDS, dejando de ser efectuada por el Comité de Ministros y que pase a ser realizada por la Asamblea Parlamentaria, ampliar su composición, dedicación a tiempo completo, y dotarle externamente de carácter judicial así como posicionar la jurisprudencia del CEDS dentro del Consejo de Europa ante nuevos escenarios y desafíos.

$2^{\text {a }}$. Mejorar la aplicación de la CSE, consumada principalmente en la adaptación y concepción de las políticas macroeconómicas de la UE con los derechos sociales, su

\footnotetext{
${ }^{14}$ La información y documentos adoptados desde esa fecha están disponibles en la web del Consejo de Europa https://www.coe.int/fr/web/turin-european-social-charter/turin-process. Un exhaustivo estudio en Jimena Quesada, L., "Retrospectiva del proceso de Turín: origen y trabajos preparatorios de la Carta Social Europea", Revista del Ministerio de Empleo y Seguridad Social, 2018, no 137, pp. 17 a 41, accesible en https://rm.coe.int/the-european-social-charter-in-the-journal-of-the-spanish-ministry-of-/168094621b.

${ }^{15}$ Véase con posterioridad «Appel à l'action de la Conférence des OING pour soutenir le «Processus de Turin» pour la Charte sociale européenne », enero 2016, https://rm.coe.int/CoERMPublicCommonSearchServices/DisplayDCTMContent?documentId=09000016 $80592 \mathrm{fe} 1$.
} 
integración en los planes de reactivación económica y en los principios generales del derecho de la UE, adecuar los indicaciones de impacto sociales y los nuevos valores de referencia según parámetros de bienestar social, fortalecer el seguimiento de las decisiones del CEDS de forma que sea paralelo al de la ejecución de las sentencias del Tribunal Europeo de Derechos Humanos, impedir a los Estados cuestionar los pronunciamientos del $\mathrm{CEDS}^{16}$, promover la creación de un procedimiento de dictamen consultivo en ese organismo por parte de los legisladores y jurisdicciones nacionales y la colaboración estrecha con los gobiernos centrales y regionales con la finalidad de asegurar la puesta en práctica de las decisiones y conclusiones.

3a. Respecto del procedimiento de reclamaciones colectivas, suscitar la ratificación de su Protocolo y de la autorización a ONG's a interponer reclamaciones, motivar su utilización y conocimiento por todos los sujetos con legitimación activa, modificar su reglamento en orden a publicar inmediatamente las decisiones de fondo así como la notificación por los Estados de las medidas dirigidas a su cumplimiento.

4a. Favorecer las sinergias entre el derecho de la UE y la CSE con un sistema normativo integrado y común de protección de los derechos, acentuar las relaciones entre todas las instancias que conforman los dos organismos, tener en cuenta, identificar y utilizar la jurisprudencia de los dos organismos de control o crear un sistema de reconocimiento recíproco. Observando este punto el CEDS confeccionó un interesante y extenso documento de trabajo sobre la Relation entre le droit de l'Union européenne et la Charte sociale européenne (2014) relacionando precisamente las conexiones entre los textos normativos de ambos organizaciones y, con ello, su viabilidad ${ }^{17}$.

5a. Realización de actuaciones encuadradas en un apartado denominado información y comunicación, en el que se incluya, la formación sobre la CSE a jueces y

\footnotetext{
${ }^{16}$ Véase, por ejemplo, la respuesta de España al referirse a este órgano en el Questionnaire relatif aux bonnes pratiques sur la mise en œuvre des droits, sociaux au niveau national realizado por el Groupe de rédaction sur les droits sociaux du Comité Directeur pour les Droits de l'homme (CDDH), 12 décembre 2017: «(...) some objections have been made, because regarding certain aspects, the ESCR's European Committee of Social Rights maintains a specific interpretation of the ESCR, not at all compulsory in light of the text of the Charter and of its interpretative Appendix. (...) This interpretation increases considerably the content of the obligations deriving from the Charter in force, thus creating legal uncertainty for the ratifying States", accessible en https://rm.coe.int/reponses-au-questionnaire-relatif-aux-bonnes-pratiquessur-la-mise-en-/16807762ac, pp. 122 et 123 o la contestación por escrito de la delegación de los Países Bajos al Comité de Ministros del Consejo de Europa, en la Résolution CM/ResChS(2015)5, sobre el pronunciamiento del CEDS en cuanto al incumplimiento de los arts. 13.4 y 31.2 de la CSE revisada en la decisión de fondo de 1 de julio de 2014 (Reclamación nº 90/2013, Conférence des Eglises européennes $(C E C))$, con referencia a los inmigrantes adultos en situación irregular, en la que califica sus interpretaciones de injustificadas, extralimitadas de su competencia -al imponer unilateralmente obligaciones que no están previstas en el Tratado- y de no realizarlas de "buena fe", incluso contrarias al propio texto, pretendiendo también disuadir al resto de Estados a que ratifiquen el Protocolo de reclamaciones colectivas. 17

Puede consultarse en https://rm.coe.int/CoERMPublicCommonSearchServices/DisplayDCTMContent?documentId=09000016 $806543 \mathrm{~cd}$.
} 
juristas nacionales e internacionales, adaptar la comunicación en relación con la CSE con la finalidad de optimizar la visibilidad, situarla en el mismo nivel que el CEDH y dinamizar su conocimiento por todos los ciudadanos, entidades y agentes sociales.

Lejos de estar ante un evento aislado y un documento teórico, su relevancia se revela en la supervisión y progreso acordado en posteriores, en particular, en la Conferencia sobre El futuro de la protección de los derechos sociales que se celebró en Bruselas el 12 y 13 de febrero de 2015, en la Conferencia interparlamentaria sobre la Carta Social Europea (conocida como Turín 2), que tuvo lugar el 17 de marzo de 2016, complementada al día siguiente por la celebración del Fórum de Turín sobre los derechos sociales en Europa y la Conferencia sobre el rol de las instituciones nacionales y europeas en la aplicación de los derechos sociales, en Nicosia el 24 de febrero de 2017.

Resulta cuestionable que este Proceso, y sus consiguientes actuaciones dirigidas a su efectividad y realidad, sea poco conocido cuando se está frente al más comprometido y relevante programa en materia de derechos sociales a nivel internacional con actuaciones concretas, es decir, no se limita al plano teórico.

Las dos organizaciones que se analizan, conscientes de ello, se han comprometido expresamente a él y, por consiguiente, con la CSE, como se mostrará a continuación.

\section{La European Network of National Human Rights Institutions (ENNHIR).}

La Red Europea de Instituciones de Derechos Humanos -European Network of National Human Rights Institutions (ENNHIR)- agrupa a más de 40 instituciones nacionales de toda Europa. En su ámbito de actuación se fija como prioridad la promoción y protección de los derechos humanos, a partir de una concepción universal, elemento clave para el establecimiento de un marco de derechos humanos nacional, regional y global, sólido y efectivo.

En coherencia con su cometido, desde sus inicios la CSE es uno de sus instrumentos normativos de referencia, el ejemplo más reciente se encuentra en la Conferencia anual celebrada el 14 de noviembre de 2019 en la que se revelan las diferentes formas de canalizar en común las actuaciones para sumar ratificaciones, los recursos que proporciona y su aplicación por las jurisdiccionales nacionales ${ }^{18}$.

En mi opinión, de entre todas las actuaciones, destaca su implicación en el Proceso de Turín, con una expresa Declaración de apoyo el 10 de octubre de 2016 en la que hace patente su consideración y respaldo. Sus principales puntos son los siguientes ${ }^{19}$ :

\footnotetext{
18 Véase http://ennhri.org/news-and-blog/role-of-nhris-in-advancing-economic-and-social-rightshighlighted-at-ennhri-annual-conference/.

19 http://ennhri.org/wp-content/uploads/2019/09/Statement-of-Support-for-the-Turin-Process-tostrengthen-Social-Rights-in-Europe.pdf.
} 
a) Se anima a los Estados Parte a apoyarlo a través de la adopción de medidas a nivel nacional.

b) Se solicita a las organizaciones internacionales regionales el establecimiento de una estrecha cooperación y trabajar hacia un marco coordinado de protección de los derechos económicos y sociales, de la que ejemplo de interés el CEDS que en sus pronunciamientos efectúa las correspondientes sinergias con el resto de instrumentos normativos.

c) Se requiere a la UE a que valorice la CSE al interpretar su legislación e integrar sus disposiciones en el procedimiento de evaluación de los derechos humanos en el curso de la formulación de políticas.

d) Se renueva la implicación con el texto europeo en sus dos versiones, por el completo marco de derechos que garantiza, entre los que citan, los relacionados con la salud, la vivienda, la protección social, las condiciones de trabajo, la libertad de organización y la protección contra la pobreza y la exclusión social.

e) Se subraya su relevancia como uno de los instrumentos que permiten la implementación de los derechos sociales, comprometiéndose a trabajar para sumar más ratificaciones de la versión revisada y del Protocolo de Reclamaciones Colectivas.

f) Se muestra la participación de las instituciones nacionales en los procedimientos de supervisión del cumplimiento del tratado en los que presentaron informes, observaciones o alegaciones, así como la invocación de sus pronunciamientos en los documentos que presentan a los gobernantes de sus países, enumerando en el Anexo siete ejemplos.

g) Finalmente, el documento termina con un compromiso en cuanto a alcanzar las prioridades que recoge el Informe final con el Consejo de Europa, la UE, los Estados y la sociedad civil para perseguir estas prioridades.

En coherencia con lo indicado, el 31 de mayo de 2017 pronunció una Declaración sobre el Pilar Europeo de los Derechos Sociales ${ }^{20}$, en la que se ha de subrayar la integración, sinergias y reenvíos al anterior ${ }^{21}$. Concretamente insiste, por un lado, en la existencia, entre los instrumentos normativos reguladores de los derechos económicos y sociales, la CSE, que no debe ser soslayada.

Y, por otro lado, recomienda que el borrador del texto comunitario elaborado sea reforzado con la el Tratado más importante de derechos sociales para reducir las divergencias entre los textos europeos y la jurisprudencia del CEDS, sugiriendo la

\footnotetext{
${ }^{20} \mathrm{http}: / /$ ennhri.org/wp-content/uploads/2019/09/Statement-on-the-European-Pillar-of-Social-Rights.pdf

${ }^{21}$ Véase De Schutter, O., "The European Pillar of Social Rights and the role of the European Social Charter in the EU legal order", 14 november 2018, https://rm.coe.int/study-on-the-european-pillar-of-social-rightsand-the-role-of-the-esc-/1680903132, pp. 1 a 73.
} 
elaboración de unos criterios comunes que sirvan a los Estados de guía para cumplir las obligaciones adquiridas en todos los Tratados.

\section{La CoE-FRA-ENNHRI-Equinet Collaborative Platform on social and economic rights.}

Conscientes de la significación de la CSE como marco legal, en el año 2015 se creó la CoE-FRA-ENNHRI-Equinet Collaborative Platform on social and economic rights ${ }^{22}$. Hasta el momento han celebrado 9 reuniones en las que no sólo este tratado es un elemento analizado, sino que se fijan directrices de actuación. A grandes rasgos, su contribución se manifiesta en tres direcciones.

En primer lugar, en su estimación como instrumento de garantía en el diseño de las políticas y prácticas nacionales enfatizando la supervisión que deben hacer los defensores del pueblo de los compromisos adquiridos de los Estados en torno a la misma. En el último Encuentro anual que han celebrado el 28 de noviembre de 2019, lo han dedicado a la justiciabilidad de los derechos sociales y económicos y el rol que tienen los órganos judiciales, quasi judiciales y las instituciones nacionales defensoras de los derechos humanos nacionales e internacionales ${ }^{23}$, en el que se han fijado como objetivos su invocación y progreso de la aplicación, como garantes de su observancia, determinando la función primordial de la jurisprudencia del CEDS.

En segundo lugar, respecto a la promoción de la aceptación de la versión revisada así como del procedimiento de reclamaciones colectivas, incluyendo su utilización, por los países que aún lo tienen pendiente.

En tercer lugar y último lugar, en la definición y delimitación del papel de las estructuras nacionales de derechos humanos para alcanzar los objetivos del Proceso de Turín, que suscriben públicamente.

Por consiguiente, es notorio el reconocimiento de la CSE por las dos entidades analizadas que debería tener su reflejo en los respectivos miembros nacionales que los configuran. Como se mostrará en los apartados siguientes, no se produce, encontrándose más bien situaciones de déficit que deberían ser corregidas para dar coherencia a las obligaciones que asumen con ocasión de su incorporación y participación.

III. Los derechos sociales como vectores de la actividad de los ombudsman: la aprehensión de la Constitución Social de Europa y de la jurisprudencia de su órgano de supervisión.

Como se ha apuntado, conocer la protección de los derechos multinivel es fundamental con la finalidad de invocar el cumplimiento de los derechos garantizados a los que los

22 Council of Europe (CoE), the European Union Fundamental Rights Agency (FRA), the European Network of National Human Rights Institutions (ENNHRI) and the European Network of Equality Bodies (EQUINET)

23 9e reunión, 28 de noviembre de 2019, Estrasburgo, https://go.coe.int/LibMM. 
estados se han comprometido. Es ineludible, en consecuencia, que las defensorías se conciencien en este sentido respecto de todas las instituciones priorizando, por la directa relación en sus competencias, la CSE.

Brevemente señalaré, que ubicada en el seno del Consejo de Europa, fue adoptada originariamente en Turín el 18 de octubre de 1961 para, según su Preámbulo, garantizar el goce de los derechos sociales sin discriminación por motivos de raza, color, sexo, religión, opinión política, proveniencia nacional u origen social, mejorar el nivel de vida y promover el bienestar de todas las categorías de la población, rurales o urbanas, por medio de instituciones y actividades apropiadas en los países que forman parte del Consejo de Europa.

La necesidad de adaptarse a la evolución y cambios de la realidad social, dio lugar a que, tras unos años, fuera ampliada y/o enmendada con la aprobación de tres Protocolos.

El primero, de 5 de mayo de 1988 (Adicional), añadió cuatro derechos que mejoraron la protección de los trabajadores. El segundo, de 21 de octubre de 1991 (Enmienda), modifica algunos artículos con objeto de mejorar "(...) la eficacia de la Carta y, en particular, el funcionamiento de su mecanismo de control". Finalmente, el importantísimo tercer y último Protocolo, de 9 de noviembre de 1995, estableció un sistema de reclamaciones colectivas y avanzar en su efectividad.

Para ordenar este panorama normativo se adoptó el 3 de mayo de 1996 la Carta Social Europea revisada. Su estructura es similar a su precedente, ampliada a 31 preceptos vinculantes -98 apartados-, que son los 19 de la anterior -se mejora la redacción de algunos de ellos-, los cuatro derechos del Protocolo de 1988 (arts. 20 a 23) e incorporó 8 nuevos, en particular, el derecho a la protección en caso de despido (art. 24), el derecho de los trabajadores a la tutela de sus créditos en caso de insolvencia de su empleador (art. 25), el derecho a la dignidad en el trabajo (art. 26), el derecho de los trabajadores con responsabilidades familiares a la igualdad de oportunidades (art. 27), el derecho de los representantes de los trabajadores a protección en la empresa y facilidades que se les deberán conceder (art. 28), el derecho a la información y consulta en los procedimientos de despido colectivo (art. 29), el derecho a protección contra la pobreza y la exclusión social (art. 30) y el derecho a la vivienda (art. 31).

El órgano de supervisión, el CEDS, realiza una labor trascendental, pronunciando conclusiones y decisiones de fondo. Obvio decir, el vector de referencia que deben ser para fundamentar las actuaciones de los defensores del pueblo.

Hasta el momento, nuestro país tiene ratificada en su totalidad la CSE de 1961 (19 derechos) y el Protocolo Adicional de 1988 (4 derechos). No está de más recordar que el propio texto es contundente al disponer que “(...) contiene obligaciones jurídicas de carácter internacional cuya aplicación está sometida únicamente al control establecido en la Parte IV" (Parte III). 
El 1 de febrero de 2019 el Consejo de Ministros adoptó un Acuerdo por el que se disponía la remisión a las Cortes Generales de la Carta Social Europea revisada y se autorizaba la manifestación del consentimiento de España para obligarse por dicha Carta. Su disolución y la convocatoria de nuevas elecciones han conllevado que decaiga y se tenga que comenzar de nuevo. El 3 de octubre de 2019, la Ministra de Trabajo en funciones informó que se ratificarán ambos los instrumentos normativos pendientes ${ }^{24}$. A falta de un gobierno en la actualidad, se sigue teniendo pendiente esa asignatura.

Por tanto, es indudable su importancia pues se está frente al principal instrumento de protección de los derechos sociales en Europa, en el que destacan, entre otros, el reconocimiento expreso de derechos como la protección contra la pobreza y la exclusión social (art. 30), la vivienda (art. 31), la protección de las personas de edad avanzada (art. 23), la protección y asistencia de los trabajadores migrantes (art. 19), la autonomía, la integración social y la participación en la vida de la comunidad de las personas minusválidas (art. 15), asistencia social y médica así como beneficios de servicios sociales (arts. 13 y 14), protección a la salud (art. 11) o a la seguridad social (art. 12). Por consiguiente, cualquier actuación, de oficio o a instancia de parte, debe inexorablemente estar unida al mismo.

En el Informe que emitió el Comisario de los Derechos Humanos tras su visita a España en junio de 2013 la menciona en seis ocasiones, entre otras, para recomendar su atención puesto que "(...) puede proporcionar orientaciones útiles a todos los Estados miembros sobre la formulación de políticas en tiempos de crisis socioeconómica, y prevenir así el aumento de la tensión social y el menoscabo de los derechos sociales y económico" 25 .

Desafortunadamente, esto no se presencia en su homólogo nacional ni en los autonómicos ${ }^{26}$, siendo censurable, incluso al primero, su poca respuesta e implicación en cuanto a la exigencia de la ratificación, a pesar incluso de haber presentado una queja el CERMI en noviembre de $2018^{27}$, en la que se limitó a solicitar información a la Secretaría de Estado de Asuntos Exteriores, decidiendo "suspender temporalmente su actuación

\footnotetext{
${ }^{24}$ Apertura del Primer encuentro de diálogo entre el Comité Europeo de Derechos Sociales y la Corte Interamericana de Derechos Humanos, Respetando los derechos sociales: lecciones aprendidas en cuanto a su eficacia, Madrid, Escuela Diplomática 3-4 de octubre de 2019, https://go.coe.int/o3nxO.

${ }^{25}$ Informe por Nils Muižnieks Comisario para los Derechos Humanos del Consejo de Europa tras su visita a España, del 3 al 7 de junio de 2013, Estrasburgo, 9 de octubre de 2013, CommDH(2013)18, pp. 1 a 48 https://www.defensordelpueblo.es/wp-

content/informesMNPEspania/europa/3_INFORME_NILS_MUIZIEKS.pdf.

${ }^{26}$ Así lo pone de relieve Terrádez Salom, al señalar que “(...) el uso de la CSE por estos organismos es casi anecdótico (...)", en "Las defensorías del pueblo españolas frente a la Carta Social Europea”, Lex Social, $\begin{array}{llllll}\text { Revista de } \quad \text { los } & \text { Deciales, } & 2015, & \mathrm{n}^{\circ} & 2,\end{array}$ https://www.upo.es/revistas/index.php/lex_social/article/view/1463, pp. 3 a 24. Se puede localizar la organización en Barcelona de un workshop en abril de 2016 en el que se invito a impartir una ponencia al Vicepresidente del CEDS, pero, en ningún caso, se centró el evento en esta norma, véase https://go.coe.int/1fPrl.

${ }^{27}$ Cáritas Española, el Movimiento Internacional ATD Cuarto Mundo, la Plataforma del Tercer Sector y la Red Europea de Lucha contra la Pobreza (EAPN España) han requerido a los responsables gubernamentales en varias ocasiones en términos similares.
} 
sobre este asunto (...) debido a la interinidad del Gobierno". Esta respuesta se contradice con los puntos acordados en las organizaciones europeas anteriormente examinadas, de las que forma parte, al igual que la ausencia y desinterés en cuanto al texto normativo en otras que lleva a cabo y documentos que elabora -verbigracia el Informe anual de 2018 o los previos-, cuando precisamente debería ser la contraria, es decir, presidir cualquier trámite en materia de derechos sociales. Con ello, incumple su mandato constitucional y, aún más grave, su servicio a los ciudadanos.

Por el contrario, sí que se pueden localizar referencias y manifestaciones de otros ombudsman europeos, que la utilizan para fundamentar respaldar jurídicamente sus peticiones a los gobernantes. A modo de ejemplo, el de Letonia en el año 2013 insistió públicamente a los responsables gubernamentales de la ratificación completa de la versión revisada, frente a la intención que había de no hacerlo del precepto que reconoce el derecho a la protección contra la pobreza, que finalmente sí que suscribió. Igualmente, en abril de 2019, en cuanto al incumplimiento de garantizar una renta mínima, les avisa del recurso al Tribunal Constitucional, sirviéndose del derecho que garantiza la CSE y se han comprometido ${ }^{28}$.

En los apartados siguientes, se va a mostrar con argumentos la relevancia aludida y las desfavorables consecuencias que se ocasionan por medio de dos derechos que recoge la CSE, el derecho a la protección contra la vivienda y la exclusión social y el derecho a la vivienda. Ambos son únicamente ejemplos de muchos más. Su elección se origina en la directa relación con numerosas peticiones a los defensores del pueblo sobre esas materias, además de por su carácter transversal y multidisciplinar, pues conectan con la mayoría de derechos sociales.

\section{El derecho a protección contra la pobreza y la exclusión social.}

La crisis iniciada hace unos años, no solo económica, sino general, de valores y principios democráticos, ha supuesto que determinados términos o expresiones se conviertan en cotidianos. Es el caso de «dignidad en el trabajo», «trabajo decente» o «umbral de la pobreza» originados en las reivindicaciones y manifestaciones sociales que, lejos de permanecer impasibles, reaccionan frente a una realidad de pérdida de las conquistas sociales adquiridas desde hace años.

En España, según los últimos datos que se proporcionan, un 26,6 \% de las personas viven en riesgo de pobreza o exclusión social, superando a bastantes países comunitarios e incluso la media $(21,7 \%)^{29}$. Estos pueden complementarse con otros más amplios no

\footnotetext{
${ }^{28}$ Véase Baltic News Service y Latvian Business News, 7 de febrero de 2013 y 5 abril de 2019, consultado en https://search.proquest.com/.

${ }^{29}$ Fuente Eurostat, Personnes en risque de pauvreté ou d'exclusion sociale par région NUTS, el porcentaje se corresponde al año 2018, http://appsso.eurostat.ec.europa.eu/nui/show.do?dataset=ilc_peps11\&lang=fr, mise à jour 5/12/2019. Véase un análisis detallado de España en el $9^{\circ}$ Informe El estado de la pobreza seguimiento del indicador de pobreza y exclusión social en España 2008-2018 que confecciona la Red Europea de Lucha contra la Pobreza y la Exclusión Social, en 
menos inquietantes, como el Informe de la Agencia de los Derechos Fundamentales de la Unión Europea Combating child poverty. An issue of fundamental rights (2018), en el que se señala que casi 25 millones de niños menores de 18 años sufren esa situación en la UE, llegando en ciertos grupos vulnerables a alcanzar el 90\%. O los que muestra UNICEF, en los que cerca de 385 millones de niños (19,5\%) del planeta viven en situación de extrema pobreza, frente al $9,2 \%$ de adultos ${ }^{30}$.

Preocupado por esta situación, el Comité de Ministros del Consejo de Europa ha adoptado el 11 de diciembre una declaración en la hace un llamamiento a los Estados y a todos los actores responsables, a luchar y colaborar para la erradicación de la pobreza infantil. En éste se menciona, por un lado, la CSE en su versión revisada que reconoce, por primera vez y como único instrumento normativo internacional, el derecho a la protección a la pobreza y la exclusión social en un precepto específico. En concreto, el art. 30, exige a las Partes a que se comprometan a "adoptar medidas en el marco de un planteamiento global y coordinado para promover el acceso efectivo, en particular, al empleo, a la vivienda, a la formación, a la enseñanza, a la cultura, y a la asistencia social y médica, de las personas que se encuentren o que corran el riesgo de encontrarse en una situación de exclusión social o de pobreza, así como de sus familias", incluyendo su adaptación en caso de ser necesaria su adaptación. De los 34 países que han ratificado ese texto, que permite hacerlo en su totalidad o parcialmente, 18 lo han hecho del precepto aludido.

La significación del precepto se puede apreciar en la interdependencia y sinergia con otros derechos reconocidos en el mismo texto, entre otros, el acceso a la salud (art. 11), la seguridad social (art. 12), la asistencia social y médica (art. 13), el beneficio de los servicios sociales (art. 14), los derechos de las personas con discapacidad (art. 15), la protección social, jurídica y económica de la familia (art. 16), la protección de la niñez para aplacar la infantilización de la pobreza (art. 17), la protección de las personas migrantes y sus familias (art. 19), la igualdad de oportunidades y trato en el empleo sin discriminación sexual como desafío relevante para paliar la feminización de la pobreza (art. 20), los derechos de las personas mayores (art. 23), el derecho a la vivienda (art. 31), sin olvidar el impacto de la cláusula de no discriminación (art. E), calificándolo, por ello, como "una especie de sufragio universal de proyección social"31.

Y, por otra parte, la monitorización que realiza del mismo el CEDS, de la que resulta una interpretación vinculante. Hasta el momento ha pronunciado en torno al mismo, por lo que se refiere al procedimiento de reclamaciones colectivas, 15 decisiones de fondo, de

https://www.eapn.es/estadodepobreza/ARCHIVO/documentos/Informe_AROPE_2019_Resumen_Ejecuti vo.pdf, pp. 1 a 17.

${ }^{30}$ Datos extraídos e https://data.unicef.org/resources/.

31 Jimena Quesada, L., "El derecho a la protección contra la pobreza y la exclusión social: discurso contra la argumentación jurídica inequitativa", Discurso de investidura como "Doctor Honoris Causa" por la Universidad Nacional de la Plata y Conferencia inaugural de la Maestría del Instituto de Derechos Humanos (17 de marzo de 2017), http://www.derechoshumanos.unlp.edu.ar/assets/files/Discurso\%20y\%20Conferencia\%20Doctor\%20Hon oris\%20Causa\%20Luis\%20Jimena\%20Quesada.pdf, pp. 5 y ss. 
las que 7 han sido de condena por su violación. En cuanto al procedimiento de informes y las conclusiones correspondientes, de un total de 53 adoptadas, 22 han sido de conformidad, 16 de no conformidad y 15 han sido pospuestas.

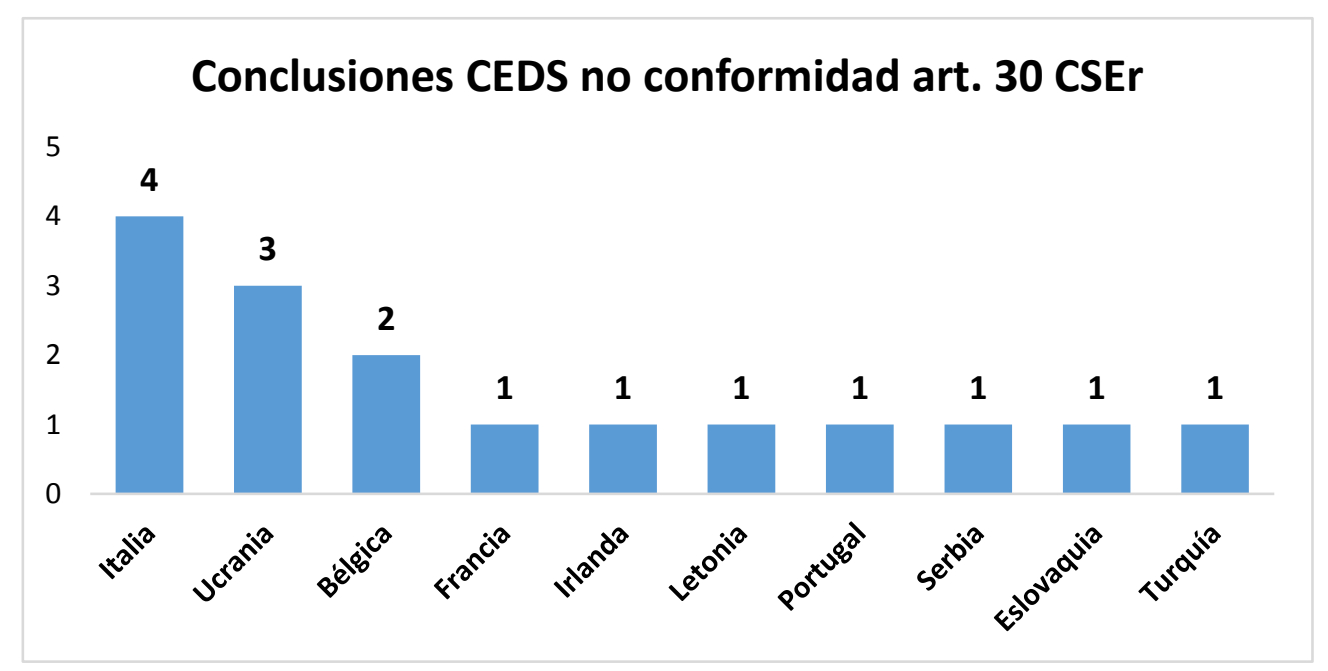

Fte: https://hudoc.esc.coe.int/fre/\#\{\%22ESCDcType\%22:[\%22Ob\%22]\} (8/11/2019). Elaboración propia.

El examen del mismo se inicia con las relevantes Observaciones interpretativas que el CEDS ha emitido, la última en las Conclusiones de 2013, que recoge las previas de las Conclusiones de 2003 y 2005, así como con los criterios fijados con ocasión de la resolución de reclamaciones colectivas. En sus primeras líneas, de nuevo, es contundente al afirmar que vivir en situación de pobreza y exclusión social atenta contra la dignidad del ser humano. Por ello, no dejar lugar a dudas en cuanto a la exigencia a los Estados de la efectividad del precepto por la vía de adoptar medidas dirigidas a favorecer el acceso a los derechos sociales fundamentales, en particular, en lo que se refiere al empleo, alojamiento, formación, educación, cultura y asistencia social y médica, incluyendo la eliminación de los posibles obstáculos que los dificulten.

El organismo europeo las precisa, en el sentido de que, no sólo deben fortalecer el acceso a los derechos sociales, sino también "su supervisión y aplicación, mejorando los procedimientos relacionados con los beneficios y servicios, así como su gestión, para proporcionar una mejor información sobre los derechos sociales y lo que proporcionan, eliminar las barreras psicológicas y socioculturales para su acceso y, si es necesario, dirigirse especialmente a los grupos y regiones más vulnerables". En este punto, considera decisivo el diálogo con los representantes de la sociedad civil y las personas que sufren estas situaciones (Decisión de fondo de 19 de octubre de 2009, Reclamación nº 51/2008, Centre européen des Droits des Roms contre France).

Con base en estas premisas, el CEDS ha resuelto sobre este artículo teniendo en cuenta dos aspectos. Por un lado, una serie de indicadores que facilitan una evaluación precisa y eficaz de las políticas, medidas y acciones acometidas desde un enfoque global y coordinado. Es fundamental el relativo al nivel de recursos, en el que se comprende también su progresión al alza, ya que es el que permite a las personas ser autónomas en 
la sociedad. Para su examen particular se atiende al porcentaje de población amenazada por la pobreza, antes y después de las transferencias sociales (comprenden las ayudas sociales por las instituciones públicas estatales o locales, entre otras, pensiones de jubilación, muerte y supervivencia, desempleo, familia, prestaciones de invalidez y enfermedad, educación, ayudas para la vivienda o asistencia social), como dato comparativo para apreciar las situaciones nacionales, sin perjuicio del recurso a otros parámetros oportunos que se han valorado en la confección de las estrategias o planes nacionales (por ejemplo, los índices sobre la lucha contra la feminización de la pobreza, los de las iniciativas para corregir fenómenos multidimensionales de pobreza y exclusión, los de evaluación de la pobreza heredada de generación en generación, etc. ).

Esta interpretación juega un papel muy importante en el marco de la crisis económica. Por ello, el CEDS incorpora, para recordarle a los Estados sus obligaciones, la relevante Introducción general que se emitió junto a las Conclusiones XIX-2 de 2009 sobre la aplicación de la Carta Social Europea en el contexto de la crisis económica global que ha pasado a convertirse en un principio general que prácticamente es reproducido en toda la jurisprudencia posterior ${ }^{32}$.

Así, es categórico al determinar que "si el aumento del paro pone en peligro los sistemas de seguridad social, en la medida en que el número de beneficiarios aumenta mientras que los ingresos obtenidos por la fiscalidad y de las cotizaciones a la seguridad social disminuyen, las Partes, al suscribir la Carta Social Europea (...) han aceptado perseguir por todos los medios útiles la realización de condiciones aptas para asegurar el ejercicio efectivo de un cierto número de derechos, especialmente el derecho a la salud, el derecho a la seguridad social, el derecho a la asistencia social y médica y el derecho a los servicios sociales", concluyendo que "la crisis económica no debe traducirse en una reducción de la protección de los derechos reconocidos por la Carta (...); los Gobiernos deben por tanto adoptar todas las medidas necesarias para conseguir que esos derechos sean efectivamente garantizados en el momento en que la necesidad de protección se hace sentir más (...)".

Añade que "(...) lo que vale en materia de derecho a la salud y a la protección social no vale menos en materia de derecho del trabajo; (...) si la crisis puede legítimamente conducir, en unos u otros ámbitos, a reorganizar los dispositivos normativos y las prácticas vigentes con vista a limitar algunos costes para los presupuestos públicos o a aligerar las cargas que pesan sobre las empresas, semejante reorganización no debería traducirse en una precarización excesiva de los beneficiarios de los derechos reconocidos por la Carta. (...). Una mayor flexibilidad en el trabajo para luchar contra el desempleo no puede conducir a privar a amplias categorías de asalariados, singularmente quienes ya no son titulares desde hace mucho tiempo de empleos estables, de sus derechos

\footnotetext{
${ }^{32}$ Nivard, C., «Comité européen des droits sociaux (CEDS): Violation de la Charte sociale européenne par les mesures «anti-crise» grecques ». Lettre Actualités-Droits-Libertes du CREDOF, 15 noviembre 2012, https://revdh.files.wordpress.com/2012/11/lettre-adl-du-credof-15-novembre-20121.pdf, p. 1.
} 
fundamentales en materia laboral, contra la arbitrariedad del empleador o los avatares de la coyuntura. Es precisamente a la instauración y al mantenimiento de tales derechos, en los dos ámbitos mencionados, a los que tienden justamente las disposiciones de la Carta. Renunciar a tales garantías tendría, a mayor abundamiento, no solamente como efecto el hacer recaer sobre los asalariados indebidamente una parte excesiva de las consecuencias de la crisis, sino incluso aceptar efectos pro-cíclicos susceptibles de agravar la crisis y de aumentar la carga de los regímenes sociales, en particular los asistenciales, a menos que ello no suponga compensar las pérdidas de recursos vinculadas al retroceso de las actividades, lo cual comportaría un atentado a las obligaciones de la Carta en materia de protección social”.

Y, por otro lado, también contempla la tasa de pobreza relativa, que se corresponde con el porcentaje de personas que viven por debajo del umbral de pobreza, fijado en el $60 \%$ de la renta media ajustada.

En este contexto, son frecuentes las referencias del CEDS en cuanto a la evaluación del Tratado como un instrumento para la protección de los derechos humanos efectivos, es decir, en ningún caso, una compilación de texto teórico (Decisión de fondo de 9 de septiembre de 1999, Reclamación no 1/1999, Commission Internationale de Juristes contre Portugal), en coherencia con Los Principios Rectores sobre la Extrema Pobreza y los Derechos Humanos ${ }^{33}$, aprobados por Resolución del Consejo de Derechos Humanos 21/11, el 27 de septiembre de 2012, que posteriormente ha aplicado en las decisiones de fondo de 25 de junio de 2010, Reclamación n $n^{\circ}$ 58/2011, Centre on Housing Rights and Evictions contre Italie y 23 de octubre de 2012, Reclamación nº 69/2011, Défense des Enfants International contre Belgique.

Específicamente, el CEDS ha interpretado el alcance del artículo 30 a los supuestos presentados integrando dos dimensiones:

a) La protección contra la pobreza desde el punto de vista de las situaciones de precariedad social. En este marco, ha definido la pobreza como estado de indigencia por la ausencia de recursos que puede sobrevenir a una persona por diferentes situaciones, entre las que pueden estar, el incumplimiento por los Estados Parte de la obligación de garantizar a todos el derecho a acceso a atención sanitaria, que debe ser accesible para toda la población, de unas rentas mínimas a las personas que se encuentran en situación de necesidad o por la falta de un enfoque coordinado que promueva el acceso efectivo a la vivienda de las personas más pobres.

b) La protección contra la exclusión social desde el punto de vista de los obstáculos existentes en cuanto a la inclusión y a la participación ciudadana. A este respecto, ha exhortado a los Estados a estimular -obligación positiva- la participación

\footnotetext{
${ }^{33}$ https://documents-dds-ny.un.org/doc/UNDOC/GEN/G12/154/63/PDF/G1215463.pdf?OpenElement. El informe contiene las recomendaciones detalladas por la Experta independiente encargada de la cuestión de los derechos humanos y la extrema pobreza, Magdalena Sepúlveda Carmona, que presentó el 6 agosto 2010, https://documents-dds-ny.un.org/doc/UNDOC/GEN/G10/153/07/PDF/G1015307.pdf?OpenElement
} 
ciudadana para superar los obstáculos derivados de la falta de representación de determinados colectivos (población de etnia gitana o romaní) en esferas sociales como la cultura, los medios de comunicación o la administración. Del mismo modo, les recuerda que este precepto no puede interpretarse de forma restrictiva puesto que la lucha contra la exclusión social es un área en la que la noción de indivisibilidad de los derechos fundamentales reviste una importancia particular. Por ello, efectúa una mención expresa al derecho al voto, así como otros derechos relacionados con la participación cívica y ciudadana, necesarios para lograr la integración y la inclusión social.

En suma, se está en presencia de un derecho que pone de manifiesto el enfoque integral de los derechos humanos, y, por tanto, su contenido y efectividad sólo se observan vinculándolo con otras disposiciones del Tratado mencionadas anteriormente. Ahora bien, una o más violaciones de otros preceptos no conlleva automática y necesariamente la del art. 30 de la CSE, es decir, no será una excepción a ese examen global y coordinado, sin perjuicio de que pueda ser pertinente.

Una vez se ha precisado el ámbito objetivo del precepto con carácter general, se debe completar materialización específica a los países que el CEDS ha desarrollado con ocasión del control de normativa o prácticas nacionales a través del procedimiento de informes.

La primera decisión de fondo en la que se invocó este precepto y dotó de efectividad a las líneas interpretativas aludidas, con resolución estimatoria, fue de 5 de diciembre de 2007, Mouvement international ATD Quart Monde contre France, Reclamación colectiva ${ }^{\circ}$ $33 / 2006$, en la que se condenó por la insuficiencia de la política en materia de alojamiento para las personas que más sufrían una situación de pobreza o exclusión social, constatando la ausencia del enfoque aludido en cuanto a su acceso. El incumplimiento no sólo se determinó en esos términos, sino también en combinación con el art. E, por la no concesión de un carnet de identidad, motivada en la ausencia de domicilio, que, además de discriminatorio frente al resto de ciudadanos, les impedía acceder a otros derechos sociales que, para su concesión, demandan esa tarjeta nacional.

Igualmente fue condenatoria la siguiente decisión de fondo de 19 de octubre de 2009, Centre européen des Droits des Roms (CEDR) contre France, Reclamación colectiva ${ }^{\circ}$ $51 / 2008$, por el vacío de una política de alojamientos para las familias itinerantes (travellers) y de etnia gitana. Si bien algunos municipios sí que adoptan medidas, otros permanecen indiferentes, produciéndose situaciones de exclusión social. Asimismo, la diferencia de tratamiento del derecho a votar y el límite del 3\% de las personas poseedoras de una tarjeta de residencia, necesario para el primero, no respeta el Tratado, de forma que, superado el porcentaje, no se otorga el título y, por derivación, se excluye, resultando afectados principalmente los colectivos citados. La indolencia frente a esta condena originó una nueva decisión de fondo el 24 de enero de 2012, originada en la Reclamación $n^{\circ}$ 64/2011 del Forum européen des Roms et des Gens du Voyage. 
El siguiente pronunciamiento condenatorio se produce al año siguiente con la decisión de fondo de 25 de junio de 2010, Centre on Housing Rights and Evictions (COHRE) contre Italie, Reclamación colectiva $\mathrm{n}^{\circ} 58 / 2009$, por falta de una política con la población romaní y sinti, la segregación en ghettos, las condiciones de vida mediocres e insuficiencia de infraestructuras y servicios públicos, estableciendo la correspondiente sinergia con la similar condena que emitió en las Conclusiones de 2009. Estos colectivos sufren una estigmatización desde hace años frente a la que el CEDS ha pronunciado una jurisprudencia que manifiesta una particular sensibilidad así como una comprometida voluntad positiva ${ }^{34}$.

La ausencia de ese enfoque coordinado entre responsables estatales y municipales, así como el seguimiento de los programas establecidos, fueron los que fundamentaron las condenas a Portugal en la decisión de fondo de 30 de junio de 2011, Centre européen des Droits des Roms (CEDR), Reclamación colectiva n ${ }^{\circ}$ 61/2010 y, de nuevo, a Francia, por discriminación en el acceso a la vivienda de los migrantes de la población romaní, en la decisión de fondo de 11 de septiembre de 2012, Médecins du Monde - International, Reclamación colectiva $n^{\circ}$ 67/2011.

Siguiendo con la supervisión de las políticas públicas, con la finalidad de que no se limiten a ser enunciados programáticos y que incluyan especialidades de determinadas agrupaciones particularmente vulnerables se examinaron los planes de Bélgica, con ocasión de la Reclamación colectiva $\mathrm{n}^{\circ}$ 62/2010, Fédération Internationale des Ligues des Droits de l'Homme (FIDH). La laguna de los requisitos que exige el precepto derivaron en una decisión de fondo condenatoria el 21 de marzo de 2010.

Otro colectivo examinado ha sido el de los discapacitados que presentan un grado de gran dependencia. Nuevamente, la deficiencia del enfoque conjunto, por no presentar datos estadísticos e información fiable que permitan y fundamenten el establecimiento de medidas para hacer frente a su situación de precariedad y la de sus familias, supuso la condena a Bélgica, (decisión de fondo de 18 de marzo de 2013, Fédération internationale des Ligues des Droits de l'Homme (FIDH), Reclamación nº 75/2011).

Para finalizar, muy relevante ha sido la decisión de fondo de 2 de julio de 2014 contra los Países Bajos, Fédération européenne des Associations nationales travaillant avec les Sans-abri (FEANTSA), Reclamación $n^{\circ} 86 / 2012$, por el desamparo de las personas sin hogar, sufriendo prácticamente por ello una situación permanente de pobreza y exclusión social.

\section{El derecho a la vivienda.}

El otro derecho objeto de examen que considero está muy relacionado con la actividad de los defensores del puesto es el relativo al de la vivienda. Recogido en el art. 31 de la CSE

\footnotetext{
${ }^{34}$ Véase el completo estudio de Jimena Quesada, L., "Las grandes líneas jurisprudenciales del Comité Europeo de Derechos Sociales: tributo a Jean Michel Belorgey", Lex Social, revista de derechos sociales, 2017, $\mathrm{n}^{\mathrm{o}} 1$, https://www.upo.es/revistas/index.php/lex social/article/view/2383, pp. 1 a 25
} 
revisada, se trata de un precepto muy relevante y, al igual que el anterior, transversal respecto del resto de disposiciones. Además, muy conectados por las condenas por violaciones conjuntas.

Expresamente determina que para garantizar su ejercicio, las Partes se comprometen a adoptar medidas destinadas a:

a) Favorecer el acceso a la vivienda de un nivel suficiente.

b) Prevenir y paliar la situación de carencia de hogar con vistas a eliminar progresivamente dicha situación.

c) Hacer asequible el precio de las viviendas a las personas que no dispongan de recursos suficientes.

Aunque no está ratificado por España, la interpretación solapada, cruzada y coherente de sus fines con el art. $16^{35}$, que reconoce el derecho de la familia a protección social, jurídica y económica, ha implicado que esté obligada en ciertos términos, al exigir a los países que lo suscriban fomentar la protección económica, jurídica y social de esa institución, especialmente mediante prestaciones sociales y familiares, disposiciones fiscales, apoyo a la construcción de viviendas adaptadas a las necesidades de las familias, ayuda a los recién casados o por medio de cualesquiera otras medidas adecuadas, con el fin de lograr las condiciones de vida indispensables para un pleno desarrollo como célula fundamental de la sociedad.

El CEDS ha emitido jurisprudencia muy relevante en torno a este precepto. Comenzando por las Observaciones interpretativas, ha pronunciado una en las Conclusiones de 2015 respecto del apartado segundo, determinando que el precepto prohíbe la expulsión de los alojamientos de urgencia si no van acompañadas de una propuesta alternativa similar.

En cuanto a las decisiones de fondo, 14 han abordado ese precepto presentando el punto común que en todas han condenado. El país que más ha recibido ha sido Francia.

\footnotetext{
${ }^{35}$ Expresamente lo acentúa el CEDS en, entre otras, la decisión de fondo de 9 de septiembre de $1999, \mathrm{~N}^{\circ}$ 01/1998 Commission internationale de Juristes (CIJ) contre Portugal, Reclamación nº 1/1998.
} 


\section{Decisiones de fondo CEDS art. 31 CSEr}

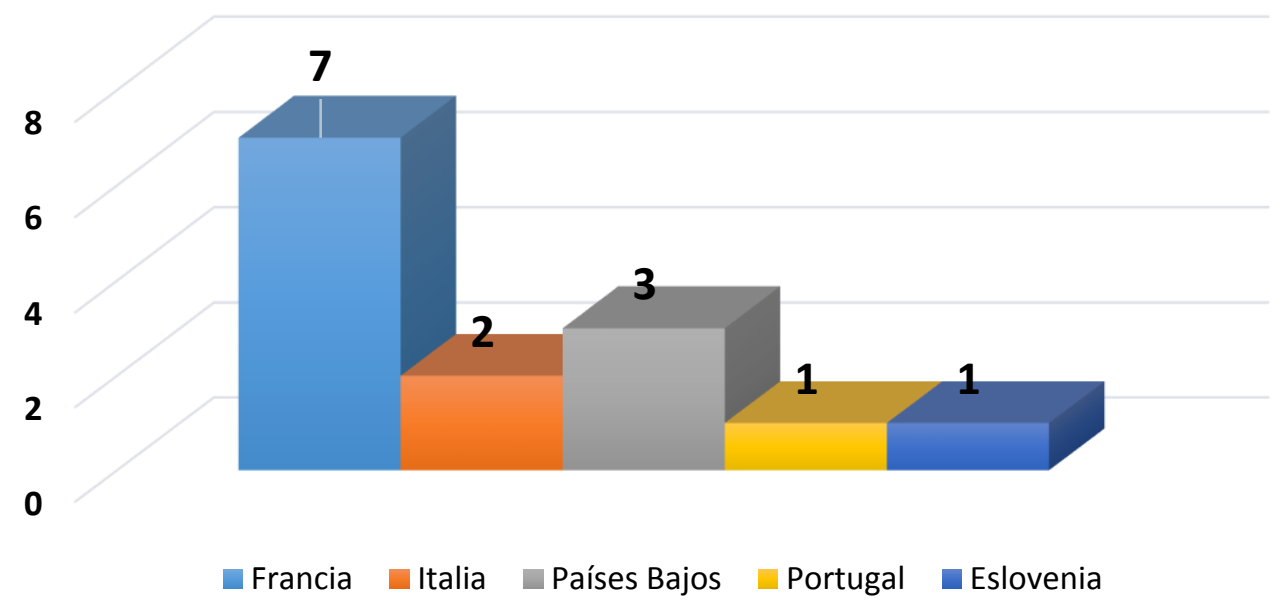

Fte: https://hudoc.esc.coe.int/ (8/11/2019). Elaboración propia.

De las 94 conclusiones en total, 44 han sido de no conformidad, 16 de conformidad y 34 pospuestas, teniendo en cuenta que el precepto en su totalidad está ratificado por sólo 10 países, y parcialmente por 4 -de éstos, 2 lo han hecho de los apartados primero y segundo y los otros dos sólo del primero-. El reparto de las primeras ha sido el siguiente:

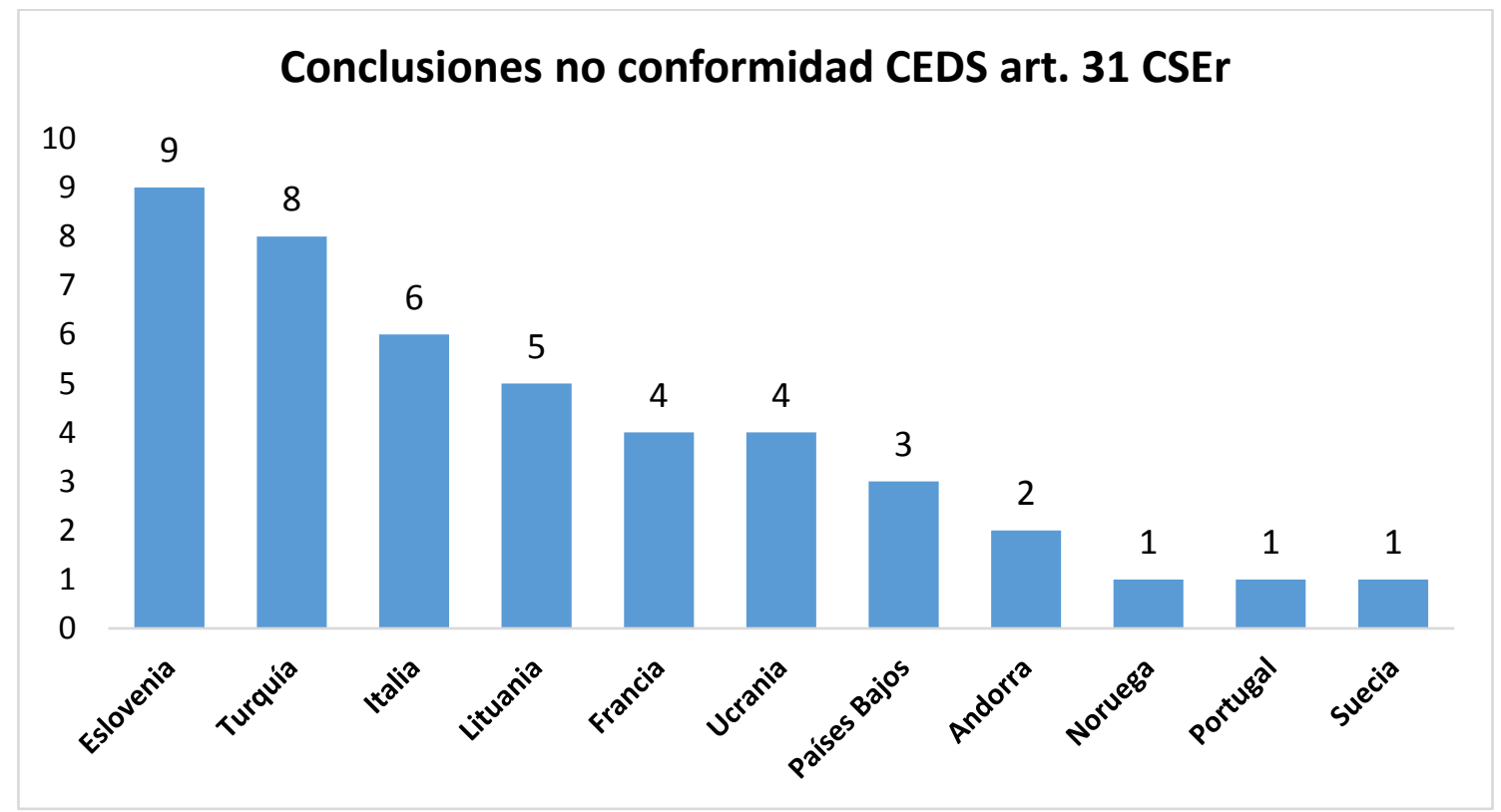

Fte: https://hudoc.esc.coe.int/ (8/11/2019). Elaboración propia.

La jurisprudencia pronunciada en la supervisión de los países es comprometida, congruente y completa, de forma que el precepto adquiere sentido y, lo más importante, realidad frente a la situación que pretende proteger. 
A este respecto, en primer lugar, en cuanto al conjunto de la disposición, se ha informado a los Estados de la obligación de adoptar medidas jurídicas y prácticas que sean necesarias $\mathrm{y}$ respondan al objetivo de proteger de forma eficaz este derecho. Si bien tienen un margen de apreciación para especificarlas, valorando el equilibrio entre los intereses generales y los de un grupo específico, así como las prioridades en la adscripción de los recursos (decisión de fondo de 18 de octubre de 2006, Centre européen des Droits des Roms (ERRC) contre Bulgarie, Reclamación no 31/2005).

Por tanto, políticas o programas que se limiten a ser programáticos no guardan los requerimientos jurídicos. En ningún momento impone una obligación de resultado pero si los Estados quieren una valoración de conformidad, están obligados a:

a) La implementación de medios normativos, financieros y operacionales adecuados que permitan avanzar realmente hacia la realización de los objetivos de la CSE. Con ello, las obligaciones no son únicamente jurídicas sino también de adscripción de recursos y de organizar los trámites y procedimientos necesarios con vista a su pleno ejercicio. En el caso de tratarse de un derecho especialmente complejo u oneroso, el Estado debe esforzarse particularmente en este sentido, mostrando un progreso en su consecución (decisión de fondo de 5 de diciembre de 2007, Mouvement International ATD Quart Monde contre France, Reclamación n 33/2006).

b) La realización de estadísticas fiables que permitan analizar las necesidades, los medios y los resultados. Precisa el CEDS que esta obligación es particularmente importante con respecto al derecho a la vivienda debido a la multiplicidad de acciones, su interacción así como de los efectos perjudiciales que pueden surgir debido a la complejidad de los mismos. Únicamente serán válidos si permiten comparar los hechos y los resultados obtenidos o el progreso realizado teniendo en cuenta las necesidades constatadas (decisión de fondo de 5 de diciembre de 2007, Mouvement International ATD Quart Monde contre France, Reclamación n 33/2006).

c) El examen regular de la efectividad de las estrategias emprendidas.

d) La definición en etapas y plazos concretos los términos de las operaciones acordadas.

e) La atención especial de su impacto respecto de los colectivos para los que se determinaron y singularmente en cuanto a los que la situación de vulnerabilidad es mayor, como sucede en los supuestos de familias y personas en situación de exclusión o pobreza.

En segundo lugar, circunscrito al apartado primero los Estados deben promover el acceso a una vivienda adecuada, fomentando su acceso a las categorías más débiles, es decir, con rentas modestas, los parados, las familias monoparentales, los jóvenes y las personas discapacitadas, principalmente los enfermos mentales. 
El concepto de «vivienda adecuada» se define como (decisión de fondo de 12 de mayo de 2017, Reclamación $n^{\circ}$ 110/2014, Federación Internacional de Derechos Humanos contra. Irlanda $\left.{ }^{36}\right)$ :

a) Una vivienda que no sea insalubre, es decir, que tenga de todos los elementos de confort necesarios, agua, calefacción, electricidad, instalaciones sanitaras, eliminación/recogida de residuos domésticos, así como el control de algunos riesgos específicos (amianto o plomo).

b) Unas viviendas que no esté hacinadas, es decir, que su tamaño se corresponda con el previsto a la capacidad del lugar dónde se reside y a la composición familiar de un hogar.

c) Un alojamiento dotado de garantías legales en cuanto a su permanencia.

Estos mínimos requeridos son exigibles no sólo a las nuevas construcciones sino también a las existentes y con independencia de si se trata de alojamientos en propiedad o en régimen de alquiler.

Se deben tomar medidas positivas prestando especial atención a la población romaní y a las personas itinerantes puesto que ambos son colectivos que tradicionalmente sufren situaciones de vulnerabilidad en esta materia, remarcando que ciertos programas de realojamiento que los segregan o aíslan a la periferia, en condiciones deplorables, vulneran el precepto (decisión de fondo de 25 de junio de 2010, Centre européen des Droits des Roms (ERRC) contre Italie, Reclamación nº 58/2009).

Es responsabilidad de las autoridades públicas garantizar que la vivienda adecuada, teniendo que servirse de, entre otros, análisis de las características del parque inmobiliario, requerir a los propietarios que no respetan sus obligaciones, regular la materia relativa al urbanismo u obligar a los arrendadores a mantener las viviendas. Los gobiernos también deben tener cuidado para evitar los cortes e interrupciones servicios esenciales como el agua, la electricidad y el teléfono.

La descentralización o transferencia competencial a organismos locales o regionales, sindicatos u organismos profesionales no exime a los Estados Partes de sus obligaciones internacionales. Por tanto, tienen la responsabilidad última (decisiones de fondo de $7 \mathrm{de}$ diciembre de 2005, Centre européen des Droits des Roms (ERRC) c. Italie, Reclamación n 27/2004 y 5 de diciembre de 2007, Fédération européenne des Associations nationales travaillant avec les Sans-abri (FEANTSA) c. France, Reclamación nº 39/2006).

\footnotetext{
${ }^{36}$ Véase también, entre otras, las decisiones de fondo de 18 de octubre de 2006, Reclamación no 31/2005, Centro de Derechos para los Gitanos Europeos contra Bulgaria, y 2 de julio de 2014, Reclamación n ${ }^{\circ}$ 86/2012, Federación Europea de Organizaciones Nacionales que trabajan con Personas sin Hogar contra los Países Bajos.
} 
Finalmente, se enmarca dentro de este apartado también la obligación de proporcionar recursos jurídicos con un coste asumible.

En tercer lugar, el compromiso respecto del apartado segundo de art. 31 incluye la prevención y reducción de las situaciones en las que se carece de hogar, es decir, los estados en los que legamente no se posee un alojamiento o, de tenerlo, carece de unos mínimos que permitan calificarlo de adecuado. Para tener una conformidad los Estados Partes deben evitar que las personas vulnerables se queden sin una vivienda, además de la implementación de una política que permita acceder a viviendas sociales (entre otras, decisión de fondo de 1 de julio de 2014, Conférence des Eglises européennes (CEC) contre Pays-Bas, Reclamación nº 90/2013)

Las expulsiones fundamentadas por la ocupación ilegal de una vivienda debe ser en la medida de lo posible evitadas $\mathrm{y}$, de producirse, procurar soluciones alternativas de realojamiento de urgencia, estable, en entornos seguros, ofrecer un período razonable de preaviso antes de ejecutarla, respetar la dignidad de los afectados, impedir que se realicen en invierno o por la noche así como ayudar económicamente, prever vías de recurso con asistencia jurídica para obtener una reparación adecuada y asegurar una indemnización en caso de producirse alguna ilegalidad, con independencia de su carácter irregular en el terrritorio (decisiones de fondo de 8 de noviembre de 2004, Centre européen des Droits des Roms (ERRC) contre Grèce, Reclamación no 15/2003 o 5 de diciembre de 2007, Fédération européenne des Associations nationales travaillant avec les Sans-abri (FEANTSA) c. France, Reclamación n ${ }^{\circ}$ 39/2006).

En cuarto y último lugar, involucra a las partes a adoptar medidas orientadas a la accesibilidad del coste del alojamiento para las personas que carecen de recursos. Se ha detallado en el sentido de que se puedan asumir los gastos iniciales (fianza o pago por adelantado), la mensualidad de alquiler y otros relacionados con la puesta en funcionamiento de los servicios esenciales, de mantenimiento o de gestiones administrativas durante un período prolongado. El examen y suficiencia se realizará atendiendo a la correspondencia entre el nivel de recursos de los más desfavorecidos y el esfuerzo de los Estados en ese sentido.

Para identificarlas, incumbe a los Estados revelar la equivalencia entre el índice de esfuerzo de los solicitantes de vivienda más desfavorecidos y su nivel de recursos (decisión de fondo de 8 de septiembre de 2009, Associations nationales travaillant avec les Sans-abri (FEANTSA) contre Slovenie, Reclamación nº 53/2008).

Finalmente, corresponde a ellos acometer medidas con la finalidad de (entre otras, decisión de fondo de 5 de diciembre de 2007, Mouvement International ATD Quart Monde contre France, Reclamación no 33/2006):

-Promover la construcción de viviendas, en particular viviendas sociales, que deben estar destinados a los más desfavorecidos. 
-Reducir la duración del período de concesión y de ser excesivos, poner a disposición recursos judiciales.

-Proporcionar ayudas y subsidios para la vivienda a las personas con ingresos bajos y a los colectivos más desfavorecidos, configurándolos como derechos individuales y, nuevamente, en caso de denegación, se deben poder articular recursos accesibles.

\section{La superación de un presente de déficits de conocimiento y aplicación.}

En los apartados precedentes se ha fundado la afirmación sostenida desde los inicios de este estudio sobre la relevancia de la CSE y de la jurisprudencia del CEDS en el ámbito de los derechos sociales. Trasladada a la actividad de los defensores del pueblo, un análisis de la misma manifiesta como se ha apuntado que, con carácter general, es escasamente referenciada como instrumento de exigibilidad en denuncias, escritos o informes, y, en caso de efectuarse, tan sólo de forma genérica, sucinta y con tendencia a la consideración como soft law ${ }^{37}$. Más crítica seré con la inclusión de menciones al carácter no vinculante de los pronunciamientos de estos organismos.

Centrándome en las primeras, el derecho a la vivienda y su protección del art. 16 de la CSE se encuentra en informes del Ararteko $^{38}$ o Resoluciones del defensor del pueblo andaluz formuladas por quejas presentadas. Específicamente en las de 1 de marzo de 2016, 17 de abril y 12 de septiembre de 2017 (Quejas 14/5231, 15/2073, 17/1564 y 14/4633) contra las consejerías autonómicas, provinciales o ayuntamientos con competencias en la materia, en las que se les demanda el respeto del precepto, que recoge el derecho de la familia a protección social, jurídica y económica, en particular (“Con miras a lograr las condiciones de vida indispensables para un pleno desarrollo de la familia, célula fundamental de la sociedad, las Partes se comprometen a fomentar la protección económica, jurídica y social de la familia, especialmente mediante prestaciones sociales y familiares, disposiciones fiscales, apoyo a la construcción de viviendas adaptadas a las necesidades de las familias, ayuda a los recién casados o por medio de cualesquiera otras medidas adecuadas").

Con fundamento, entre otros, en este precepto y en el artículo 17 (Derecho de los niños y adolescentes a protección social, jurídica y económica), el Justicia de Aragón ${ }^{39}$, presentó una queja en materia de ayudas de comedor, limitándose a la mención.

La exigibilidad del precepto ha sido empleada por el Síndic de Greuges en alguna ocasión, como reacción al recurso de inconstitucionalidad ( $n^{\circ}$ 2501/2016) que presentó el Estado contra la Ley del Parlamento de Cataluña 24/2015, de 29 de julio, de medidas urgentes

\footnotetext{
${ }^{37}$ Caracteriza la situación Terrádez Salom de "timidez a la hora de mencionar normas internacionales", en "Las defensorías del pueblo españolas..." op. cit., $\quad$ p. 339 https://www.upo.es/revistas/index.php/lex_social/article/view/1463.

38 http://www.ararteko.net/RecursosWeb/DOCUMENTOS/1/1_876_3.pdf, pp. 478 y 479.

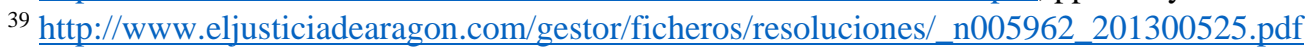


para afrontar la emergencia en el ámbito de la vivienda y la pobreza energética, en la que advierte al Estado que la "decisión no va en la línea del sentido y el contenido de los derechos de la Carta social europea (...) [y por ello] se dirigirá al Consejo de Europa, al Comité de Derechos Sociales y al Comisario de Derechos Humanos de Europa para denunciar y contrastar la decisión respecto a los estándares europeos (...)"40.

Entre las otras disposiciones invocadas, han sido la recomendación al actual Ministerio de Trabajo, Migraciones y Seguridad Social de la inclusión en la tipificación legal del acoso, de la definición contenida en el artículo 26.2 de la CSE revisada “(...) puesto que el texto vincula estas conductas al derecho a la dignidad en el trabajo y las define en su artículo 26.2, como «actos condenables o explícitamente hostiles dirigidos de manera reiterada contra cualquier trabajador en el lugar de trabajo o en relación con el trabajo»" (Queja n $^{\circ}$ 14004136, 5 de marzo de 2014 ${ }^{41}$ )

Para terminar, alguna referencia aislada se encuentra en materia de protección de las personas con discapacidad (Informe extraordinario de la institución del Ararteko al Parlamento Vasco, 2017 ${ }^{42}$ ).

Las resoluciones, escritos e informes apuntados, en principio, deben tener favorable acogida y valoración, no así, como he avanzado, alguna referencia encontrada en cuanto a que "(...) las decisiones de este Comité no tienen carácter vinculante, debe considerarse que el cumplimiento de buena fe de un Tratado por un Estado firmante debe obligarle a no apartarse de la doctrina de su Comité sin una justificación razonable" ${ }^{\text {43 }}$.

Semejantes afirmaciones muestran el escaso y equívoco conocimiento del carácter vinculante del Tratado y de la jurisprudencia de su órgano, ajenas, además, a todos los pronunciamientos de primera y segunda instancia judicial que así lo han reconocido y aplicado $^{44}$.

\section{Desafíos y líneas de actuación.}

Ante la situación constatada en la actualidad, el defensor de pueblo puede contribuir de forma relevante respecto a la CSE y, en consecuencia, fortalecer su actividad a la vez que corresponder de forma más efectiva a los requerimientos de los ciudadanos.

\footnotetext{
${ }^{40}$ http://www.sindic.cat/es/page.asp?id=53\&ui=4110.

${ }^{41} \mathrm{https}: / / \mathrm{www}$.defensordelpueblo.es/resoluciones/regulacion-del-acoso-laboral-o-mobbing-2/

${ }^{42} \mathrm{http}: / /$ www.ararteko.net/RecursosWeb/DOCUMENTOS/1/0_4346_3.pdf, p. 49

${ }^{43}$ Resolución del Defensor del Pueblo Andaluz formulada en la queja 15/2073 dirigida a Consejería de Fomento y Vivienda, Delegación Territorial de Fomento y Vivienda en Córdoba, en http://www.defensordelpuebloandaluz.es/pedimos-que-no-se-ejecute-el-desahucio-hasta-disponer-de-unaalternativa-habitacional.

${ }^{44}$ Una relación completa de todos los de primera y segunda instancia en Salcedo Beltrán, C., "Derechos sociales y su garantía: la ineludible aprehensión, disposición e implementación de Carta Social Europea (Constitución Social de Europa)", Revista de Derecho Social, 2018, n 83, pp. 45-74.
} 
En este sentido, las directrices a seguir, fundamentalmente serían las siguientes ${ }^{45}$ :

a) Implicación y respaldo de las peticiones de ratificación de la versión revisada de la CSE y del Protocolo de Reclamaciones Colectivas de 1995. La significación de este punto se corrobora fácilmente si se atiende, entre otros, al apuntado Informe emitido por el Comisario para los Derechos Humanos del Consejo de Europa (2013), en el que ya en el primer párrafo, tras el resumen, se realiza un llamamiento específico a España para que se adhiera a estos dos instrumentos normativos.

Similar indicación se encuentra en el Documento temático La protección de los derechos humanos en tiempos de crisis (2013), en este caso, dirigida a todos los países del Consejo de Europa y respecto de todos los instrumentos europeos e internacionales de derechos humanos en el campo de los derechos económicos y sociales (además de las dos referencias apuntadas incluye el Convenio Europeo de Seguridad Social y el Protocolo Facultativo del Pacto Internacional de Derechos Económicos, Sociales y Culturales y las decisiones de sus órganos de control), con el fin de que puedan ser justiciables ante los tribunales nacionales ${ }^{46}$.

b) Incorporar la CSE y la jurisprudencia del CEDS como centro de cualquier actuación en materia de derechos sociales. Algunas de las instituciones homólogas de otros países son conscientes de la trascendencia de este reto desde hace años como se ha demostrado ${ }^{47}$.

Se trataría de una "sinergia" desde el momento en que el órgano europeo, entre los elementos de valoración que tiene en cuenta cuando emite sus pronunciamientos, están las quejas que han podido recibir las defensorías y su consiguiente actuación ${ }^{48}$.

Por tanto, sería una correspondencia que evidenciaría la equivalente consideración entre los organismos, la apreciación integral de todo el ordenamiento jurídico además de manifestar la aprehensión y compromiso con el Tratado más trascendente sobre derechos sociales.

c) Exigibilidad a todas las instituciones del Estado del respeto y cumplimiento de los derechos ratificados y de la interpretación que efectúen sus órganos de verificación,

\footnotetext{
${ }^{45}$ Stangos, P., "Guaranteeing social rights: a shared responsability", en International Ombudsmand Workshop Human rights challenges now: the ombdsmand facing threats, Barcelona, 26-27 abril 2016, pp. 1 a

https://rm.coe.int/CoERMPublicCommonSearchServices/DisplayDCTMContent?documentId=09000016 $\underline{80650 \mathrm{e} 6 \mathrm{f}}$

${ }^{46}$ CommDH/IssuePaper(2013)2, p. 9, https://rm.coe.int/09000016806da858.

${ }^{47}$ Vid Valenti, S., The role of the ombudsman in the defence of social rights in times of economic crisis, Workshop Debriefing Paper, 3-4 September 2009 St. Petersburg (Russian Federation), University of Padua, p. 13, http://unipd-centrodirittiumani.it/public/docs/Times_of Crisis_definitivo.pdf

48 Jimena Quesada, L., «La sinergia con las defensorías del pueblo e instituciones análogas: Experiencia del Comité Europeo de Derechos Sociales (CEDS)", en AA.VV. (Escobar Roca, G.,), La protección de los derechos humanos por las defensorías del pueblo. Actas del I Congreso Internacional del PRADPI, Madrid, 2013, Dykinson, pp. 598 y ss.
} 
en cumplimiento del art. 96 de la Constitución española y de la Ley 25/2014, de 27 de noviembre, de Tratados y otros acuerdos internacionales, en línea con los tribunales de primera y segunda instancia, contando, además, con el respaldo de la sentencia del Tribunal Constitucional 140/2018, de 20 de diciembre. En esta actuación debe lógicamente incluirse los pronunciamientos del CEDS, vinculantes que, a día de hoy, deben ser considerados como jurisprudencia.

La necesidad de acometer esta directriz se comprueba con las reclamaciones que los ciudadanos cada vez más están presentando, exigiendo derechos garantizados en la CSE. A modo de ejemplo, el 17 de mayo de 2018 se registró una reclamación al defensor del pueblo español, en materia de rentas mínimas por diversas entidades de lucha contra la pobreza. En ella se pide el respaldo e investigación del defensor del pueblo español con base en el artículo 13 de la CSE (derecho a la asistencia social y médica) y el compromiso adquirido de los Estados, entre los que se encuentra el nuestro, de "velar porque toda persona que no disponga de recursos suficientes y no esté en condiciones de conseguirlo por su propio esfuerzo o de recibirlos de otras fuentes, especialmente por vía de prestaciones de un régimen de seguridad social, pueda obtener una asistencia adecuada y, en caso de enfermedad, los cuidados que exija su estado".

El supuesto denunciado es el aumento de suspensiones de rentas mínimas percibidas por familias en situación de gran precariedad por parte de la administración autonómica, requiriendo el respeto de la normativa que regula esta prestación, en particular, la CSE. Para ello, se remiten a las conclusiones emitidas por el CEDS en las que condenó al país por condicionar su concesión o mantenimiento a criterios ajenos a la continuidad de la situación de necesidad, obviando que el precepto ha sido interpretado en el sentido de que únicamente debe condicionarse a ese punto (Conclusiones XXI-1 2016).

No está de más recordar en este sentido que la CSE así como las constataciones y denuncias del CEDS a los Estados respecto de su compromiso de asegurar un nivel de vida decente a los ciudadanos, fueron el instrumento principal que propició la aprobación el 23 de enero de 2018 de la Resolución 2197 (2018) de la Asamblea Parlamentaria dirigida a la instauración de una renta básica en los países miembros del Consejo de Europa.

d) Para finalizar, contribución a la difusión de este Tratado, muy desconocido como se ha demostrado, de diferentes formas, entre otras, incluir una sección en los informes que emiten, en las webs institucionales (enlace al apartado de la web del Consejo de Europa en la que se pueden consultar todas las conclusiones y decisiones de fondo), comunicación de las conclusiones e incluso decisiones de fondo respecto de otros países, si el precepto examinado forma parte de los ratificados e incluso, una traducción de las mismas al lenguaje del país ${ }^{49}$.

\footnotetext{
${ }^{49}$ Stangos, P., “Guaranteeing social rights: a shared responsibility... », cit. pp. 8 y 9. 


\section{Reflexiones finales.}

A lo largo de este estudio se ha podido comprobar que la afirmación con la que se inició en cuanto a la caracterización de la CSE como la Constitución Social de Europa, es incuestionable. Los ejemplos examinados son sólo una muestra de muchos más, y, con ello, la necesidad de aprehender y aceptar que, cualquier referencia o actuación relativa a los derechos sociales y sus garantías que realicen las defensorías del pueblo, debe efectuarse con este Tratado, el más significativo y consistente con sus objetivos.

Esto se confirma, además, con las reclamaciones que se interponen al CEDS, muy relevantes y que abordarán materias trascendentales en la actualidad, algunas ya admitidas a trámite, otras pendientes de la decisión al respecto.

Así, sin ánimo de realizar una enumeración exhaustiva están las quince -se corresponde con el número de países que pueden ser demandados por el procedimiento- del Groupe européen des femmes diplômées des universités, Reclamaciones colectivas $\mathrm{n}^{\circ} 124$ a 138 , frente a los incumplimientos en materia de desigualdad salarial y de condiciones de trabajo (acceso a puestos relevantes) entre hombres y mujeres, resueltas en la sesión de diciembre de 2019 pero pendientes de su publicación en cumplimiento del art. 8.2 del Protocolo de Reclamaciones colectivas o la decisión de fondo de la Reclamación colectiva n ${ }^{\circ}$ 158/2017, Confederazione Generale Italiana del Lavoro (CGIL) contra Italia, que abordará uno de los asuntos más controvertidos de las reformas laborales de éste país o Francia, el de las indemnizaciones sujetas a un baremo y su compatibilidad con el art. 24 de la $\mathrm{CSE}^{50}$.

En el siglo XXI los Estados violan derechos sociales y permanecen impasibles. El ordenamiento jurídico está integrado por un conjunto de fuentes, nacionales e internacionales, que deben ser observadas y exigidas en términos equivalentes por todas las instituciones. Los defensores del pueblo deben ser un ejemplo en ese sentido como garantes de los derechos humanos al servicio de la sociedad.

\section{Bibliografía}

-AA.VV. (Coord. Huber, D). Artisans de l'europe. 30 témoignages pour 70 ans d'Histoire. 1949-2019, Strasbourg 2019, La Nuée Bleue/Les Editions du Quotidien.

-Álvarez Vélez, M.I., "El Defensor del Pueblo estatal y los defensores autonómicos: instituciones de garantía de los derechos", en AA.VV. (Coord. Álvarez Vélez, M.I. y Vidal Prado, C.), La Constitución Española: 1978-2018, Madrid, 2018, Francis Lefebvre

\footnotetext{
50 Véase un análisis completo en Salcedo Beltrán, C., "Sinergias entre la OIT y los instrumentos internacionales de protección de los derechos sociales: estado actual y perspectivas", Estudios financieros. Revista de trabajo y seguridad social: Comentarios, casos prácticos: recursos humanos, 2019, $\mathrm{n}^{\circ}$ 434, pp. 184 a 188.
} 
-Calvo Cirujano, F., "La supresión de instituciones en las comunidades autónomas: el ejemplo de Castilla-La Mancha", en AA.VV. (Coord. Pau i Vall, F.), El parlamento y el defensor del pueblo, XXII Jornadas de la Asociación Española de Letrados de Parlamentos, Madrid, 2016, Tecnos.

-De Schutter, O., "The European Pillar of Social Rights and the role of the European Social Charter in the EU legal order", 14 november 2018, https://rm.coe.int/study-on-theeuropean-pillar-of-social-rights-and-the-role-of-the-esc-/1680903132

-Del Rey Ruiz, M. y Martínez Alarcón, M.L., "Vigencia y Necesidad de un Defensor del Pueblo para Castilla-La Mancha", Revista de Estudios Jurídicos, 2013, nº 13.

-Fernández Rodríguez, J.J, “Defensor del Pueblo y defensorías autonómicas: Reflexiones sobre sus relaciones y posición recíproca", Teoría y realidad constitucional, 2010, $\mathrm{n}^{\circ} 23$, http://revistas.uned.es/index.php/TRC/article/view/6922/6620.

-Jimena Quesada, L., «La sinergia con las defensorías del pueblo e instituciones análogas: Experiencia del Comité Europeo de Derechos Sociales (CEDS)", en AA.VV. (Escobar Roca, G.,), La protección de los derechos humanos por las defensorías del pueblo. Actas del I Congreso Internacional del PRADPI, Madrid, 2013, Dykinson.

-Jimena Quesada, L., "El último bastión en defensa de los derechos sociales: La Carta Social Europea”. Revista Jurídica Universidad Autónoma de Madrid, 2014, no 29. https://revistas.uam.es/revistajuridica/article/view/5607.

-Jimena Quesada, L., "El derecho a la protección contra la pobreza y la exclusión social: discurso contra la argumentación jurídica inequitativa", Discurso de investidura como "Doctor Honoris Causa" por la Universidad Nacional de la Plata y Conferencia inaugural de la Maestría del Instituto de Derechos Humanos (17 de marzo de 2017), http://www.derechoshumanos.unlp.edu.ar/assets/files/Discurso\%20y\%20Conferencia\% 20Doctor\%20Honoris\%20Causa\%20Luis\%20Jimena\%20Quesada.pdf

-Jimena Quesada, L., "Las grandes líneas jurisprudenciales del Comité Europeo de Derechos Sociales: tributo a Jean Michel Belorgey", Lex Social, revista de derechos sociales, 2017, n 1, https://www.upo.es/revistas/index.php/lex_social/article/view/2383

-Jimena Quesada, L., "Retrospectiva del proceso de Turín: origen y trabajos preparatorios de la Carta Social Europea", Revista del Ministerio de Empleo y Seguridad Social, 2018, $\mathrm{n}^{\mathrm{o}} 137$.

-Malinowsky, J., "Pour la défense de Cendrillon », en https://70.coe.int/fr/display-story//asset_publisher/i0obV0uCSWii/content/in-defence-of-cinderella.

-Montilla Marcos, J.A., "El Informe CORA”, Observatorio de Derecho Público, IDP, 15 junio 2016, http://idpbarcelona.net/el-informe-cora/

-Nivard, C., «Comité européen des droits sociaux (CEDS): Violation de la Charte sociale européenne par les mesures «anti-crise» grecques ». Lettre Actualités-Droits-Libertes $d u$ 
CREDOF, 15 noviembre 2012, https://revdh.files.wordpress.com/2012/11/lettre-adl-ducredof-15-novembre-20121.pdf

-Salcedo Beltrán, C., "Derechos sociales y su garantía: la ineludible aprehensión, disposición e implementación de Carta Social Europea (Constitución Social de Europa)", Revista de Derecho Social, 2018, nº 83.

-Salcedo Beltrán, C., "Sinergias entre la OIT y los instrumentos internacionales de protección de los derechos sociales: estado actual y perspectivas", Estudios financieros. Revista de trabajo y seguridad social: Comentarios, casos prácticos: recursos humanos, 2019, no 434.

-Sánchez Saudinós al suponer una ampliación de mandato nacional. En "Artículo 54", en AA.VV. (Dirs. Pérez Tremps, P. y Sáiz Arnaiz, A.), Comentario a la Constitución Española: 40 aniversario 1978-2018. Libro-homenaje a Luis López Guerra, Tomo I, Valencia, 2018, Tirant lo Blanch.

-Stangos, P., "Guaranteeing social rights: a shared responsability", en International Ombudsmand Workshop Human rights challenges now: the ombdsmand facing threats, Barcelona, 26-27 abril 2016

-Terrádez Salom, D., Las defensorías del pueblo españolas frente a la Carta Social Europea", Lex Social, Revista de los Derechos Sociales, 2015, $\mathrm{n}^{\circ} \quad 2$, https://www.upo.es/revistas/index.php/lex_social/article/view/1463

-Valenti, S., The role of the ombudsman in the defence of social rights in times of economic crisis, Workshop Debriefing Paper, 3-4 September 2009 St. Petersburg (Russian Federation), University of Padua. 